\title{
MAPA DA CRÍTICA DE RODAPÉ PAULISTA (1920-1950)
}

Pedro Bueno de Melo Serrano

RESUMO: Este artigo dedica-se a mapear a crítica literária paulista praticada em jornais entre as décadas de 1920 e 1950. Após uma introdução sobre as características gerais da modalidade e sobre a relação entre Rio de Janeiro e São Paulo como polos da cultura brasileira no período, quatro jornais paulistas foram tomados para pesquisa detalhada a respeito da publicação de crítica. A partir dos resultados obtidos, pretende-se contribuir para o aprofundamento das discussões sobre a crítica literária brasileira do período e, dentro dela, da crítica literária paulista.

PALAVRAS-CHAVE: Crítica de rodapé; Crítica literária brasileira; Crítica literária paulista.

ABSTRACT: This article is dedicated towards mapping the São Paulo literary criticism practiced between the decades of 1920 and 1950 in newspapers. After an introduction on the genre's general characteristics and on the relationship between Rio de Janeiro and São Paulo as Brazilian cultural poles at the time, four São Paulo newspapers were taken for detailed research about criticism publication. Taking the obtained results, we intend to contribute for the deepening of discussions about Brazilian literary criticism of the time and, within it, São Paulo literary criticism.

KEYWORDS: Footnote critics; Brazilian literary criticism; São Paulo literary criticism. 
A crítica literária brasileira, como modalidade de produção intelectual ou como gênero literário, teve expressiva vitalidade na primeira parte do século xx. Um observador atento de jornais, revistas e livros do período poderá notar a recorrência dos temas ligados à literatura e ao comentário de livros entre os debates intelectuais. Se a tradição da crítica literária nacional se havia iniciado, ainda no século XIX, com os nomes de Sílvio Romero, José Veríssimo e Araripe Júnior, da chamada “geração de 1870", a partir das primeiras décadas do século seguinte a crítica se instituiu como instância permanente de avaliação no meio literário. ${ }^{1}$

Seu espaço predominante de veiculação foi o jornal e, em menor medida, as revistas e publicações especializadas. Havia uma referência de estilo ancorada no jornalismo literário francês, em especial nas figuras de Sainte-Beuve (1804-1969) e Thibaudet (1874-1936). Junto a isso, as condições do sistema intelectual brasileiro levaram os intelectuais ao domínio jornalístico. A passagem do século XIX ao xx marcou a emergência da "grande imprensa" no país, o que significou a transformação dos jornais em empreendimentos capitalistas estruturados. Num momento de fraca especialização das atividades do pensamento e de incipiência dos espaços de profissionalização ligados ao mercado editorial e às universidades, a imprensa restava como espaço de publicação e de trabalho para a maioria dos escritores, isto é, para o setor da classe dominante que tinha no trabalho intelectual sua frente prioritária de atuação, de obtenção de prestígio e de construção de carreira. ${ }^{2}$ Atuando nos periódicos em funções várias, os homens de letras podiam obter, além de alguma notoriedade, recursos financeiros que complementavam orçamentos auferidos, na maioria das vezes, em profissões ligadas à advocacia, ao magistério e ao serviço público. ${ }^{3}$

Essa característica teve implicações contraditórias. Poucas vezes a crítica literária, por meio da avaliação de livros novos, da classificação de movimentos e escolas, do julgamento de vanguardas etc., fez-se tão influente no meio cultural. Os críticos

\footnotetext{
1 Martins, Wilson. A crítica literária no Brasil. 2. ed. Rio de Janeiro: Francisco Alves, 1983, vol. I, 575 p. 2 BOURDieu, Pierre. As regras da arte. Gênese e estrutura do campo literário. 2 ed., reimpressão. Tradução de Maria Lúcia Machado. São Paulo: Companhia das Letras, 2010, 431 p. 3 SODRÉ, Nelson Werneck. História da imprensa no Brasil. 4. ed. São Paulo: Intercom; Porto Alegre: EDIPUCRS, 2011, pp. 429-32.
} 
tornaram-se "personalidades" que marcaram a cena literária do país e instituíram padrões de julgamento. Mas o que a imprensa proporcionou em publicidade impôs, também, em amadorismo, e a crítica da época não chegou a ser exercida de forma especializada como hoje a conhecemos nas universidades. Havia uma mescla permanente entre literatura, política e jornalismo, frente à qual os críticos atuavam como comentadores abrangentes dos temas da cultura, da conjuntura e das humanidades. Sua formação era ainda embebida no autodidatismo e na tradição polímata, em que a crítica, como prática erudita, servia para manter em contato os membros da elite intelectual, por meio de uma rede de referências e de elogios recíprocos nos artigos publicados. Todo escritor ou jornalista, independentemente de formação especializada, estava apto para exercê-la.

$\mathrm{Na}$ análise da literatura, esse tipo de crítica foi enquadrado dentro do que se convencionou designar como "impressionismo" - tido este como indicador geral de uma crítica não especializada em que sobressaía o peso das opiniões individuais dos autores. A “impressão" era o recurso básico utilizado para a análise. Mais do que por métodos solidamente instituídos, o crítico orientava-se por impulsos subjetivos, por ideias e visões que lhe ocorriam no ato da leitura; e sua tarefa, assim, era transmitir para o leitor esses elementos, orientados pela sensibilidade. Com o passar do tempo, o impressionismo, cujos componentes eram indissociáveis da crítica feita em jornal, passou a ser objeto de questionamento, pois se armou um debate sobre a necessidade de adoção de critérios objetivos de análise, que tomassem a obra literária - e não a subjetividade do crítico, suas opiniões políticas ou conceitos de mundo - como elemento central. Também se impôs um deslocamento gradual dos jornais em direção às universidades como espaços prioritários de elaboração. Ainda assim, é possível indicar que o impressionismo foi predominante até, pelo menos, a década de 1950, isto é, durante a fase enfocada neste artigo. ${ }^{4}$

4 Sobre o tema, consultar: candido, Antonio. "Prefácio”. In: Barreto, Plínio. Páginas avulsas. Rio de Janeiro: José Olympio, 1958, pp. 13-18. CANDido, Antonio. “Sérgio Milliet, o crítico”. In: Milliet, Sérgio. Diário crítico: 1940-1943. São Paulo: Martins, 1981, vol. I, pp. 11-30. LAfETÁ, José Luiz. 1930: a crítica e o modernismo. 2. ed. São Paulo: Duas Cidades/Editora 34, 200o, pp. 61-66. LINs, Álvaro. "Impressionismo e erudição”. In: MAIA, Eduardo Cesar (org.). Álvaro Lins, sobre crítica e críticos. Recife: Cepe, 2012, pp. 43-52. 
A crítica literária nos jornais ficou conhecida como "crítica de rodapé". O nome consagrou-se em decorrência de os artigos serem quase sempre publicados ao pé das páginas, os rodapés, ocupando cerca de um quarto do espaço das folhas - eram, portanto, artigos extensos. Os rodapés tinham a especificidade de: i) serem periódicos (com frequência semanal); II) serem assinados sempre por um mesmo crítico (o crítico "titular" ou "profissional"); e iii) terem títulos permanentes em suas seções (como "Livros Novos" ou "Vida Literária"). Outros espaços de publicação eram os suplementos e páginas literárias, além das páginas reservadas a articulistas, com contribuições avulsas.

Embora inúmeros autores, como Süssekind, ${ }^{5}$ Johnson $^{6}$ e Sorá,7 tenham apontado a relevância da crítica de rodapé, faz falta uma visão aprofundada sobre o tema. Este artigo pretende suprir essa lacuna, mapeando os críticos que escreveram nos principais jornais paulistas e indicando traços de sua biografia e trajetória intelectual. ${ }^{8}$

II

Rio de Janeiro e São Paulo reuniam os críticos e jornais mais influentes do país. A então capital federal era centro político e cultural e detinha o monopólio das ferramentas de produção e de consagração; concentrava, portanto, os críticos literários mais renomados. Já São Paulo destacou-se no sentido da inovação no campo da cultura. Apoiado no mecenato oligárquico, o modernismo paulista foi mais "radicalizado" do que o carioca, fenômeno atribuído por Candido" aos pesos distintos da "tradição" nas duas cidades.

5 süssekind, Flora. “Rodapés, tratados e ensaios: a formação da crítica brasileira moderna”. In: Papéis colados. 2. ed. Rio de Janeiro: Editora da UFRJ, 2002, pp. 15-36.

6 Johnson, Randal. “A dinâmica do campo literário brasileiro (1930-1945)”. Revista USP. São Paulo, n. 26, pp. 164-181, jun./ago. 1995.

7 SORÁ, Gustavo. Brasilianas: José Olympio e a gênese do mercado editorial brasileiro. São Paulo: Edusp; Com-Arte, 2010, pp. 108-14.

8 Baseio-me em minha pesquisa de mestrado: serrano, Pedro Bueno de Melo. A crítica bandeirante (1920-1950). 145 p. Dissertação (Mestrado em Sociologia). Universidade de São Paulo. São Paulo, 2016. 9 CANDido, Antonio. "Entre Duas Cidades". In: marras, Stelio (org.). Atualidade de Sérgio Buarque de Holanda. São Paulo: Edusp, Instituto de Estudos Brasileiros, 2012, pp. 13-17. 
Além disso, frentes culturais e científicas de trabalho surgiram justamente como armas da elite regional na disputa de hegemonia durante os anos 1930. ${ }^{10}$

Nesse contexto, o ambiente universitário vicejou em terras paulistas, com a Faculdade de Filosofia, Ciências e Letras (FFCL/USP) e a Escola Livre de Sociologia e Política (ELSP). Foi criado, ainda, em 1935, o Departamento Municipal de Cultura (DMC), que denotava uma agitação e um adensamento culturais crescentes. Sobre São Paulo, Arruda $^{11}$ aponta, no marco do meio do século $\mathrm{xx}$, a emersão definitiva de um caráter "metropolitano moderno". Na confluência do modernismo (no nível da estética literária e artística), da consolidação da academia e da criação de um diversificado aparelho institucional, São Paulo passou a reivindicar para si a imagem de uma "meca da cultura e das ciências brasileiras".

No tocante à crítica, tal fato possibilitou experiências consideradas inovadoras e que apontavam para uma especialização acadêmica do gênero. Exemplo consagrado nesse sentido foi a revista Clima, ${ }^{12}$ publicada entre 1941 e 1944, sob patrocínio de Alfredo Mesquita e idealização de Lourival Gomes Machado. A revista surgiu como uma publicação especializada em crítica, o que era raro, e segmentada entre temas da literatura, cinema, teatro, arte, música etc. Em Clima, deu-se a estreia de Antonio Candido, ao lado de colegas da FFCL/USP que movimentaram o meio intelectual paulista e brasileiro.

Segundo Süssekind, ${ }^{13}$ houve então a abertura de uma disputa tensionada entre a "crítica de rodapé" e a "crítica universitária", que se resolveria tempos depois, visto que a força dos jornais manteve o primeiro modelo em vigor até meados do século xx. De fato, ao passo que a relevância de Clima é incontestável, uma visão completa sobre a crí-

10 "Os dirigentes da oligarquia paulista atribuem as derrotas sofridas em 1930 e 1932 à carência de quadros especializados para o trabalho político e cultural e, escorados nesse diagnóstico, passam a condicionar suas pretensões de mando no plano federal à criação de inesperados instrumentos de luta: A Escola de Sociologia e Política, a Faculdade de Filosofia, Ciências e Letras, no contexto da Universidade de São Paulo, e o Departamento Municipal de Cultura são iniciativas que se inscrevem nesse projeto." MICELI, Sergio. Intelectuais à brasileira. 2. ed. São Paulo: Companhia das Letras, 2012, p. 101.

11 ARrudA, Maria Arminda do Nascimento. Metrópole e cultura. São Paulo no meio século Xx. Bauru/sP: Edusc, 2001, p. 101 (Coleção Ciências Sociais).

12 Pontes, Heloísa. Destinos mistos: os críticos do grupo Clima em São Paulo (1940-1968). São Paulo: Companhia das Letras, 1998, 297 p.

13 SÜSSEKIND, Flora. "Rodapés, tratados e ensaios: a formação da crítica brasileira moderna”. In: Papéis colados. Op. cit., p. 16. 
tica do período revela que os influxos renovadores da revista foram, antes, manifestação isolada; um novo padrão ligado à universidade viria a desenvolver-se apenas a partir do ingresso de Antonio Candido na área de Teoria Literária e Literatura Comparada da usp, quase duas décadas depois, em 1961.

III

Se tomarmos o contexto carioca, alguns dos nomes fortes da crítica de rodapé foram: Alceu Amoroso Lima (1893-1983), cujo pseudônimo era Tristão de Ataíde, crítico titular de O Jornal por muitas décadas; ${ }^{14}$ Agripino Grieco (1888-1973), consagrado em O Jornal e no Boletim de Ariel; ${ }^{15}$ Álvaro Lins (1912-1970), tido como o "imperador da crítica literária" e crítico do Correio da Manhã ${ }^{16}$ Humberto de Campos (1886-1934), antecessor de Lins no mesmo jornal:;7 Octávio de Faria (1908-1980) e Otto Maria Carpeaux (190o1978), que publicaram em O Jornal e em outras folhas; ${ }^{18}$ além de Afrânio Coutinho (1911200o), que escreveu no Diário de Notícias e teve posição sugestiva entre os críticos de rodapé por defender o chamado new-criticism ${ }^{19}$ de origem anglo-americana, fato que o deixou, frequentemente, isolado entre seus pares. ${ }^{20}$

Todavia, em São Paulo, teria sido a publicação de rodapés igualmente intensa? Quais eram os críticos do estado? Entre eles, quais os protagonistas e os coadjuvantes? Que características de origem social, trajetória intelectual e atuação crítica possuíram?

\footnotetext{
14 GOMES Júnior, Guilherme Simões. “Crítica, combate e deriva do campo literário em Alceu Amoroso Lima”. Tempo Social (Revista de Sociologia da UsP). São Paulo, vol. 23, n. 2, pp. 101-33, 2011.

15 LAFETÁ, José Luiz. 1930: a crítica e o modernismo. Op. cit., pp. 39-74.

16 BOLle, Adélia Bezerra de Meneses. A obra crítica de Álvaro Lins e sua função histórica. Petrópolis: Vozes, 1979, $117 \mathrm{p}$.

17 MICELI, Sergio. Intelectuais à brasileira. Op. cit., pp. 56-7.

18 FERnANDEs, Ronaldo Costa. "História da literatura ocidental: a obra monumental de Otto Maria Carpeaux”. In: CARPEAux, Otto Maria. História da literatura ocidental. São Paulo: Leya, 2011, vol. I, pp. 19-43.

19 O chamado new criticism impôs-se como contraponto ao impressionismo, ao defender uma separação definitiva entre o texto literário, por um lado, e o autor e o meio, por outro. Segundo aquela doutrina, a tarefa do crítico seria tomar o texto literário como objeto exclusivo em busca de uma análise estética - isto invalidava as "impressões" e a subjetividade como critérios de interpretação.

20 JACKSON, Luiz \& BLANCO, Alejandro. Sociologia no espelho. Ensaístas, cientistas sociais e críticos literários no Brasil e na Argentina (1930-1970). São Paulo: Editora 34, 2014, pp. $205-6$.
} 
Para responder a essas perguntas, foi realizada pesquisa em arquivo ${ }^{21}$ sobre quatro jornais (Correio Paulistano, Diário de São Paulo, Folha da Manhã e O Estado de S. Paulo), com foco no período entre as décadas de 1920 e 1950. Em seguida, foram investigadas as biografias dos críticos anotados. ${ }^{22}$

Um primeiro aspecto destacável foi o volume expressivo de rodapés, páginas e suplementos literários publicados, especialmente, a partir da década de 1930. Mais prestigiado jornal entre os quatro, $O$ Estado de S. Paulo ${ }^{23}$ já abria espaço para rodapés desde a década anterior, na seção intitulada "Bibliografia". Em seguida, os demais estruturaram suas seções. Em termos de páginas e suplementos, cumpre mencionar ao menos os suplementos literários da Folha da Manhã e d'O Estado de S. Paulo, bastante influentes. ${ }^{24} \mathrm{~A}$ Tabela 1 mostra cada um dos rodapés divididos pelos jornais através do tempo.

21 A pesquisa em arquivo foi realizada no Arquivo Público do Estado de São Paulo.

22 As informações biográficas sobre os críticos foram colhidas na bibliografia geral e nos seguintes dicionários especializados: ABREU, Alzira Alves de [et al.] Dicionário histórico-biográfico brasileiro pós-1930. 2 ed. Rio de Janeiro: Editora FGv/CPDoc, 2001, 5 volumes. Luft, Celso Pedro. Dicionário de literatura portuguesa e brasileira. 2 ed. São Paulo: Globo, 1973, 406 p. MElo, Luis Correia de. Dicionário de autores paulistas. São Paulo: Comissão do Iv Centenário da cidade de São Paulo - Serviço de Comemorações Culturais, 1954, 678 p. MENESES, Raimundo de. Dicionário literário brasileiro. 2 ed. Rio de Janeiro: Livros Técnicos e Científicos, 1978, 803 p.

23 “Todos deviam admitir que escrever em O Estado de S. Paulo era honra insuperável.” sodré, Nelson Werneck. A luta pela cultura. Rio de Janeiro: Bertrand Brasil, 1990, p. 12.

24 Sobre a diversidade de páginas e suplementos literários, bem como sobre os rodapés de outras temáticas, consultar: NunEs, Mônica de Fátima Rodrigues. Paulicéia literária: páginas e suplementos literários em jornais paulistanos (1920-1964). 257 p. Tese (Doutorado em Comunicação Social). Universidade Metodista de São Paulo. São Bernardo do Campo/sp, 2007. Sobre o Suplemento Literário d'O Estado de S. Paulo, que circulou de 1956 a 1974, ver: LoREnzotti, Elizabeth. Suplemento literário: que falta ele faz!. São Paulo: Imprensa Oficial do Estado de São Paulo, 2007, 208 p. 
TABELA 1: RODAPÉS PERIÓDICOS DE CRÍTICA LITERÁRIA NOS JORNAIS PAULISTAS

\begin{tabular}{|c|c|c|c|c|}
\hline & $\begin{array}{c}\text { Correio } \\
\text { Paulistano }\end{array}$ & $\begin{array}{l}\text { Diário de São Paulo } \\
\text { (Diários Associados) }\end{array}$ & Folha da Manhã & O Estado de S. Paulo \\
\hline Anos 1920 & - & - & - & $\begin{array}{l}\text { "Bibliografia" } \\
\text { "Livros Novos" }\end{array}$ \\
\hline Anos 1930 & "Livros Novos" & $\begin{array}{l}\text { "Reportagem Literária" } \\
\text { "Vida Literária" } \\
\text { "Letras Estrangeiras" }\end{array}$ & "Livros e Ideias" & "Livros Novos" \\
\hline Anos 1940 & $\begin{array}{l}\text { "Livros Novos" } \\
\text { "Vida Literária" }\end{array}$ & $\begin{array}{c}\text { "Vida Literária" } \\
\text { “Letras Estrangeiras" } \\
\text { "Livros Novos" } \\
\text { "Notas de Crítica } \\
\text { Literária" }\end{array}$ & $\begin{array}{l}\text { "Notas de Crítica } \\
\text { Literária" } \\
\text { "Jornal de Crítica" } \\
\text { "Letras e Problemas } \\
\text { Universais" } \\
\text { "Apontamentos de } \\
\text { leitura" }\end{array}$ & $\begin{array}{l}\text { "Livros e Ideias" } \\
\text { "Últimos Livros" }\end{array}$ \\
\hline Anos 1950 & "Vida Literária" & Rodapés sem títulos & $\begin{array}{l}\text { "Letras e Problemas } \\
\text { Universais" } \\
\text { "Apontamentos de } \\
\text { Leitura" } \\
\text { "Letras Estrangeiras" } \\
\text { "Crítica" }\end{array}$ & "Últimos Livros" \\
\hline $\begin{array}{l}\text { Suplementos/ } \\
\text { Páginas literárias }\end{array}$ & Sim & Sim & Sim & Sim \\
\hline
\end{tabular}


Acerca dos críticos, deve-se notar que a irrupção do modernismo, vista por Arruda ${ }^{25}$ como marco de ingresso paulista no cenário intelectual mais amplo, conduziu escritores do movimento às páginas dos jornais e à crítica literária. Numa primeira fase, sobretudo no Correio Paulistano, de forma esparsa; depois, em outras folhas. Mário de Andrade (1893-1945) foi crítico de rodapé no Diário de Notícias e colunista n’O Estado de S. Paulo. Lafetá ${ }^{26}$ apontou-o como um precursor do "projeto estético" na crítica literária, contraposto ao "projeto ideológico", ou seja, ao engajamento político predominante nos anos 1930. Oswald de Andrade (1890-1954) foi articulista neste mesmo jornal, ficando conhecido pelo estilo verborrágico e polêmico. ${ }^{27}$ Já Antônio de Alcântara Machado (1901-1935) chegou a assumir a crítica titular no Diário de São Paulo. Entre os modernistas, de conjunto, notou-se uma forma fluida de contribuição para os jornais, diferente da maior parte dos críticos titulares por ser mais aberta a experimentações no campo estético e ideológico.

Mas não apenas os homens de 1922 fizeram crítica. Por exemplo, Plínio Barreto (1882-1958), que foi figura dominante n'O Estado de S. Paulo, construiu carreira nas interfaces do jornalismo, da advocacia e da política, por fora do movimento. ${ }^{28}$ Suas análises e juízos priorizavam os pré-modernos, ${ }^{29} \mathrm{e}$ seus artigos eram guiados, grosso modo, pelo intuito de anunciar e resenhar livros novos, em modelo recorrente na crítica de rodapé por conta da pressão dos interesses editoriais. Barreto foi também dirigente do Partido Democrático, homem de confiança da família Mesquita e chegou a elegerse deputado federal pela UDN em 1945. A fraqueza de sua elaboração crítica, somada à politização de seus textos, muitas vezes excessivamente datados, talvez explique $\mathrm{o}$

25 ARruda, Maria Arminda do Nascimento. "Modernismo e regionalismo no Brasil: entre inovação e tradição". Tempo Social (Revista de Sociologia da USP). São Paulo, vol. 23, n. 2, pp. 191-212, 2011. BOSI, Alfredo. História concisa da literatura brasileira. 48 ed. São Paulo: Cultrix, 2012, pp. 323-403.

26 LAfETÁ, José Luiz. 1930: a crítica e o modernismo. Op. cit., pp. 39-74.

27 Uma amostra dos artigos de Oswald encontra-se em: Andrade, Oswald de. Ponta de lança: polêmica. 2 ed. Rio de Janeiro: Civilização Brasileira, 1971, 110 p.

28 CABral, André da Costa. Escritores brasileiros na correspondência passiva do crítico literário Plínio Barreto. 326 p. Dissertação (Mestrado em Literatura Brasileira). Universidade de São Paulo, São Paulo, 2009.

29 Barreto havia sido redator-chefe da Revista do Brasil, a mais importante publicação literária da Primeira República, entre 1916 e 1918, espaço a partir do qual se relacionou com os escritores e as obras pré-modernistas. 
apagamento do autor nas discussões acadêmicas atuais, ainda que tenha gozado de reputação elevada em vida.

No decorrer da década de 1940, foi Sérgio Milliet (1898-1966) quem se apoderou dos rodapés d'O Estado de S. Paulo. Sua trajetória foi ligada à poesia (como poeta moderno), à sociologia (área em que era formado e exercera a docência) e à crítica literária e de arte (a que se dedicou na extensa fase final de sua carreira). Junto a isso, Milliet dirigiu o DMC, a Biblioteca Municipal e outras instituições que o alçaram a posição influente. Muitos o apontaram como figura-chave no meio cultural paulista após a morte de Mário de Andrade, em $1945 .^{30}$ Sua crítica era altamente considerada, em particular na discussão dos estreantes e da poesia, gênero de que mais se aproximou; foi ele um dos primeiros a consagrarem a chamada "geração de 1945", por exemplo, entre outros escritores e poetas. Sua prosa fluente era chegada ao estilo da crônica e do ensaio e foi definida por Candido ${ }^{31}$ como "ondulante e variada", característica de um "espírito crítico" de excelência.

O sucessor de Milliet foi Wilson Martins (1921-2010), que ficou conhecido por assumir os rodapés d'O Estado de S. Paulo durante a fase do prestigiado Suplemento Literário. Martins teve uma intensa produção crítica nos jornais durante toda a vida, o que levou a que publicasse impressionantes catorze volumes de livros compilando seus artigos..$^{32}$ Além disso, dedicou-se à historiografia literária. O mais interessante em seu perfil foi a reivindicação, algo extemporânea, do impressionismo - o autor defendeu a crítica jornalística pelo século xx adentro, já numa época em que o modelo caíra em desuso.

Outra figura a ser citada é Nelson Werneck Sodré (1911-1999), crítico titular por décadas no Correio Paulistano..$^{33}$ Sua atuação intelectual foi pautada pelas vicissitudes de uma carreira militar em que chegou à alta patente para depois ser preso, exilado e conduzido à reserva, nos anos 1960. Isso porque seu engajamento se deu na ala à esquer-

\footnotetext{
30 CAmpos, Regina Salgado. Ceticismo e responsabilidade: Gide e Montaigne na obra crítica de Sérgio Milliet. São Paulo: Annablume, 1996, 377 p. GonçALves, Lisbeth Rebollo. Sérgio Milliet, crítico de arte. São Paulo: Perspectiva; Edusp, 1992, 198 p.

31 CANDido, Antonio. “Sérgio Milliet, o crítico”. In: Milliet, Sérgio. Diário crítico: 1940-1943. Op. cit., pp. 15-21.

32 martins, Wilson. Pontos de vista (crítica literária). São Paulo: T. A. Queiroz, 1991, vol. 1-14. 33 BARros, Luitgarde Oliveira Cavalcanti. Nelson Werneck Sodré: um perfil intelectual. Rio de Janeiro: Ed. Uerj; Ed. Ufal, 2011, 222 p.
} 
da de um exército polarizado entre "legalistas" e "golpistas". Os artigos do autor foram muitas vezes pautados pela política ou norteados pelo método materialista de análise, de inspiração marxista, pouco usual no contexto brasileiro. Sem dúvida, contribuiu para sua importância menor em comparação com colegas o fato de ter publicado em jornal decadente - o Correio Paulistano era órgão oficial do Partido Republicano Paulista e entrou em crise após 1930.

É curioso notar que nos jornais Folha da Manhã e Diário de São Paulo houve participação mais acentuada de críticos cariocas do que de paulistas. Sendo parte da rede dos Diários Associados de Assis Chateaubriand, o Diário de São Paulo reproduzia, localmente, artigos originários da capital do país; já a Folha da Manhã, recém-lançada no mercado, agia de acordo com lógica comercial publicando críticos cariocas que alavancavam suas vendas.

Entre os paulistas, nesses jornais, Antonio Candido foi um dos poucos a desenvolverem uma crítica sofisticada. Ele foi titular da Folha da Manhã entre 1943 e 1945 e do Diário de São Paulo entre 1945 e $19477^{34}$ Vale lembrar que o autor surgia como um jovem crítico literário formado em Ciências Sociais pela FFCL/USP e projetado no meio intelectual a partir de Clima. Seu trânsito pelos rodapés no começo da carreira reafirma a força que a modalidade possuía. Ramassote ${ }^{35}$ observa que, já de início, Candido propunha uma nova dicção em crítica literária, sob influência das ferramentas de análise da sociologia e do ensino universitário, sem abandonar de todo os parâmetros do impressionismo jornalístico. ${ }^{36}$

\footnotetext{
34 Candido foi indicado para o posto por Plínio Barreto, que escrevera no Diário de São Paulo entre 1940 e 1945, durante a expropriação d'O Estado de S. Paulo pelo Estado Novo. Além dos dois, no Diário de São Paulo e na Folha da Manhã, os paulistas foram apenas críticos de ocasião, sem um trabalho aprofundado. 35 RAMASSOTE, Rodrigo Martins. A vida das formas literárias: crítica literária e ciências sociais no pensamento de Antonio Candido. 291 p. Tese (Doutorado em Antropologia Social). Universidade de Campinas. Campinas, 2013.

36 Sobre os artigos de Candido nos rodapés, ver: CANDido, Antonio. Brigada ligeira. 4 ed. Rio de Janeiro: Ouro sobre Azul, 2011, 109 p. CANDido, Antonio. O observador literário. Rio de Janeiro: Ouro sobre Azul, 2004, $116 \mathrm{p}$.
} 
Para sistematizar "protagonistas" e "coadjuvantes", registrou-se o tempo durante o qual cada crítico foi titular em rodapés. A Tabela 2 sistematiza as informações, realçando em negrito os titulares por período igual ou superior a cinco anos em São Paulo.

O grupo dos "protagonistas" pode ser definido em torno de: Plínio Barreto ("Bibliografia" e "Livros Novos"), Sérgio Milliet ("Últimos Livros") e Wilson Martins ("Últimos Livros"), n’O Estado de S. Paulo; Nelson Werneck Sodré ("Livros Novos" e "Vida Literária"), no Correio Paulistano; Tristão de Ataíde ("Letras e Problemas Universais"), na Folha da Manhã; Agripino Grieco (sem título), Tristão de Ataíde ("Letras Estrangeiras" e "Vida Literária"), Otto Maria Carpeaux (sem título) e Plínio Barreto ("Livros Novos"), no Diário de São Paulo. Entre os que contribuíram fora dos rodapés, chamaram a atenção nomes como Mário de Andrade, Oswald de Andrade e Sérgio Buarque de Holanda, n’O Estado de S. Paulo, e outros escritores do modernismo, como Cassiano Ricardo, Menotti del Picchia, Plínio Salgado e Cândido Motta Filho, no Correio Paulistano.

Além deles, houve grande volume de críticos de ocasião, alguns dos quais chegaram a se estabelecer nos rodapés por anos, mas não com a mesma importância que os nomes apresentados acima. Nesses casos, em geral, tratava-se ou de escritores e intelectuais que escreviam rodapés em meio às tarefas que assumiam na imprensa e em busca de auferir brilho extra às suas carreiras, ou de jornalistas, isto é, membros das diretorias dos jornais e "focas de redação" que se encarregavam circunstancialmente da resenha de livros.

Muitos podem ser vistos sob a óptica do primeiro bloco, como Fernando de Azevedo $^{37}$ e Sud Mennucci ${ }^{38}$ (n’O Estado de S. Paulo); Osmar Pimentel, ${ }^{39}$ José Geraldo

\footnotetext{
37 Fernando de Azevedo (1894-1974) atuou por longo tempo na redação do jornal, mas apenas por alguns anos assinou o rodapé "Bibliografia”. Ele atuava em múltiplas frentes no funcionalismo público, no magistério, no jornalismo e no campo editorial. Desempenhou papel decisivo na reforma do ensino do país ao ocupar o posto de Secretário de Educação e Saúde, em 1947, e foi diretor da coleção Brasilianas da Companhia Editora Nacional entre 1931 e 1946, iniciativa editorial decisiva no período.

38 Sud Mennucci (1892-1948) assinou o rodapé "Bibliografia", em que falava com frequência sobre pedagogia e educação. Isso porque sua carreira fora estabelecida no magistério do ensino secundário. $\mathrm{O}$ autor chegou a ser Diretor-Geral de Ensino e dirigiu o recenseamento escolar do estado de São Paulo nos anos 1920. 39 Osmar Pimentel (1912-1989) assinou o rodapé “Apontamentos de Leitura”. Era natural do Rio de Janeiro, mas se formara pela Faculdade de Direito de São Paulo, onde atuou no magistério de ensino superior e no jornalismo.
} 
Tabela 2: Críticos titulares em cada jornal

\begin{tabular}{|c|c|c|c|c|}
\hline & $\begin{array}{c}\text { Correio } \\
\text { Paulistano }\end{array}$ & $\begin{array}{l}\text { Diário de São Paulo } \\
\text { (Diários Associados) }\end{array}$ & Folha da Manhã & $\begin{array}{c}\text { O Estado de S. } \\
\text { Paulo }\end{array}$ \\
\hline Anos 1920 & - & - & - & $\begin{array}{l}\text { Plínio Barreto; } \\
\text { Fernando de } \\
\text { Azevedo; Sud } \\
\text { Mennucci; }\end{array}$ \\
\hline Anos 1930 & $\begin{array}{l}\text { Nelson } \\
\text { Werneck } \\
\text { Sodré; }\end{array}$ & $\begin{array}{c}\text { Antônio de Alcântara } \\
\text { Machado; Agripino } \\
\text { Grieco; Otávio Tarquínio } \\
\text { de Sousa; Tristão } \\
\text { de Ataíde; Euríalo } \\
\text { Cannabrava }\end{array}$ & Rubens do Amaral; & Plínio Barreto; \\
\hline Anos 1940 & $\begin{array}{l}\text { Nelson } \\
\text { Werneck } \\
\text { Sodré; } \\
\text { Nuto } \\
\text { Sant'anna }\end{array}$ & $\begin{array}{c}\text { Tristão de Ataíde; } \\
\text { Agripino Grieco; } \\
\text { Euríalo Cannabrava; } \\
\text { Plínio Barreto; Antonio } \\
\text { Candido; }\end{array}$ & $\begin{array}{c}\text { Antonio Candido; } \\
\text { Álvaro Lins; Tristão } \\
\text { de Ataíde; Osmar } \\
\text { Pimentel }\end{array}$ & $\begin{array}{l}\text { Mario Donato; } \\
\text { Edmundo Rossi; } \\
\text { N. Duarte Silva; J. } \\
\text { O. Orlandi; Sérgio } \\
\text { Milliet }\end{array}$ \\
\hline Anos 1950 & $\begin{array}{c}\text { Nelson } \\
\text { Werneck } \\
\text { Sodré }\end{array}$ & Otto Maria Carpeaux & $\begin{array}{l}\text { Tristão de Ataíde; } \\
\text { Osmar Pimentel; José } \\
\text { Geraldo Vieira; Pedro } \\
\text { Xisto; Fausto Cunha; } \\
\text { Péricles Eugênio da } \\
\text { Silva Ramos }\end{array}$ & $\begin{array}{l}\text { Sérgio Milliet; } \\
\text { Wilson Martins }\end{array}$ \\
\hline
\end{tabular}


Vieira, ${ }^{40}$ Pedro Xisto, Fausto Cunha e Péricles Eugênio da Silva Ramos ${ }^{41}$ (na Folha da Manhã); e Otávio Tarquínio de Sousa, ${ }^{42}$ Euríalo Cannabrava ${ }^{43}$ e Antônio de Alcântara Machado (no Diário de São Paulo). Entre os “jornalistas", podem ser citados Mário Donato, Edmundo Rossi, N. Duarte Silva e J. O. Orlandi ${ }^{44}$ (n'O Estado de S. Paulo); Nuto Sant'anna ${ }^{45}$ (no Correio Paulistano); e Rubens do Amaral ${ }^{46}$ (na Folha da Manhã). Cabe mencionar a aparição breve de Álvaro Lins na Folha da Manhã, entre os anos de 1946 e 1947. Diversamente dos cariocas Diário de Notícias e O Jornal, o Correio da Manhã, aparentemente, expandia pouco suas publicações para além do Rio de Janeiro. Contudo, a presença esporádica em São Paulo não diminuía a importância de Lins na imprensa carioca e, por extensão, no cenário literário brasileiro, que foi sempre muito grande.

40 José Geraldo Vieira (1897-1977) assinou o rodapé “Letras Estrangeiras”. Além de exercer as profissões de médico e jornalista, foi um importante romancista de seu tempo.

41 Fausto Cunha (1889-1959), Pedro Xisto (1901-1987) e Péricles Eugênio da Silva Ramos (1919-1992) assinaram em mutirão (cada um publicava um artigo por semana) o rodapé "Crítica". O primeiro atuava basicamente como jornalista e produtor de ensaios literários. Já os demais tiveram como gênero preferencial a poesia. Xisto foi ligado aos concretistas, enquanto Ramos despontou na "geração de 1945 " e teve expressiva atuação como poeta e tradutor.

42 Otávio Tarquínio de Sousa (1889-1959) assinou o rodapé “Vida Literária”. Os artigos eram reproduzidos a partir do periódico carioca O Jornal, que encabeçava a rede dos Diários Associados. Formado em direito, Sousa conciliava a carreira de jornalista com a de funcionário público, uma combinação recorrente à época.

43 Euríalo Cannabrava (1908-1978) assinou o rodapé “Letras Estrangeiras", em reprodução de seus artigos para O Jornal. O objeto prioritário das discussões do autor era a filosofia e a psicologia, áreas em que era formado e lecionava.

44 Donato (1915-1992), Rossi (1917-?), Silva (1905-?) e Orlandi (1891-?), mantiveram por mutirão o rodapé "Livros e Ideias". A seção veio à tona no período em que O Estado de S. Paulo sofreu intervenção estatal. Com a saída de Plínio Barreto, que até então fazia o rodapé, a solução buscada pelos novos diretores do jornal foi mobilizar "focas de redação" que mantivessem a seção de crítica; em seguida, esta seria comandada por Sérgio Milliet, interrompendo o mutirão anterior. As informações biográficas sobre os autores são escassas.

45 Nuto Sant’anna (1889-1975) assinou o rodapé “Livros Novos". Sua carreira fora constituída entre o magistério no ensino superior (nas áreas da farmácia e odontologia) e no funcionalismo público.

46 Rubens do Amaral (1890-1964) assinou o rodapé "Livros e Ideias". O autor atuou em múltiplas áreas entre o jornalismo e a política, tendo sido, por exemplo, deputado estadual eleito em 1947, pela UDN, e vereador de São Paulo em mais de um mandato.

106. SERRANO, Pedro Bueno de Melo. Mapa da crítica de rodapé paulista 
Algumas conclusões devem ser pontuadas com base nos dados apresentados acima. Primeiramente, nota-se que havia grande dinamismo na presença da crítica literária em todos os quatro periódicos paulistas. Isso afasta a hipótese de que a crítica paulista tivesse sido pouco intensa em comparação à do Rio de Janeiro, apenas pelo fato de a capital federal concentrar a maior parte dos recursos culturais. Pelo contrário, a agitação local foi desde o princípio digna de nota, sem dúvida devido ao peso do modernismo e da criação das universidades.

Em contrapartida, poucos críticos, nos jornais de São Paulo, escreveram por períodos extensos, havendo, na realidade, número significativo de jornalistas e intelectuais que foram críticos de ocasião. Esse fato reafirma a caracterização da crítica de rodapé, inclusive em São Paulo, como uma atividade pouco especializada e de caráter flutuante entre gênero literário e modalidade jornalística. Mesmo aqueles que se notabilizaram por uma atuação duradoura pouco avançaram no desenvolvimento de alguma dicção inédita que destoasse das características gerais do impressionismo. Os traços renovadores apresentados em Clima, como já apontado, embora tenham fomentado debates já nos anos 1940, não chegaram a se desenvolver efetivamente nos jornais.

Por fim, notou-se que a presença dos críticos cariocas consagrados foi abundante, especialmente na Folha da Manhã e no Diário de São Paulo. Isso parece reforçar a noção de que o centro gravitacional do gênero, no período, era o Rio de Janeiro, visto serem reproduzidos em São Paulo artigos publicados originalmente nos jornais cariocas. Dessa forma, a consolidação de São Paulo como o polo dominante da crítica literária do país viria a se firmar, somente, a partir da década de 1960, com a atuação de Antonio Candido no DTLLC/UsP. Antes disso, o cânone da crítica impressionista era carioca.

Este artigo se encerra antes abrindo do que fechando debates, com o apontamento de temas interessantes para serem aprofundados em pesquisas futuras.

Pedro Bueno de Melo Serrano é Mestre em Sociologia pela Universidade de São Paulo e doutorando na mesma instituição 